(2) Open Access Full Text Article

\title{
Impact of mild to moderate COPD on feasibility and prognosis in non-small cell lung cancer patients who received chemotherapy
}

This article was published in the following Dove Press journal: International Journal of COPD

\section{Norihito Omote \\ Naozumi Hashimoto \\ Masahiro Morise \\ Koji Sakamoto \\ Shinichi Miyazaki \\ Akira Ando \\ Yoshio Nakahara \\ Yoshinori Hasegawa}

Department of Respiratory Medicine, Nagoya University Graduate School of Medicine, Nagoya, Japan
Correspondence: Norihito Omote Department of Respiratory Medicine, Nagoya University Graduate School of Medicine, 65 Tsurumai-cho, Showa-ku, Nagoya 466-8550, Japan

Tel +8I 527442167

Fax +8I 527442176

Email nori05692000@yahoo.co.jp
Background: Non-small cell lung cancer (NSCLC) is the predominant cause of death in patients with COPD, and the severity of COPD in NSCLC patients is classified mainly as mild to moderate. Most advanced NSCLC patients with mild to moderate COPD are treated with chemotherapy; however, the feasibility for and prognosis after chemotherapy of these patients are not well understood. The aim of this study was to elucidate the impact of mild to moderate COPD on the feasibility for and prognosis after chemotherapy in NSCLC patients.

Patients and methods: A retrospective review was performed on 268 NSCLC patients who received first-line chemotherapy from 2009 to 2014 in our institution. Finally, 85 evaluable patients were included in this study. The clinical characteristics, toxicity profile, objective response rate, and prognosis were analyzed and compared between patients with mild to moderate COPD and those without COPD (non-COPD).

Results: Forty-three patients were classified as COPD (27 cases mild and 16 cases moderate) and 42 patients as non-COPD. The COPD group were older and had fewer never-smokers than the non-COPD group. The objective response rate did not differ between groups $(p=0.14)$. There was no significant difference in overall survival between COPD and non-COPD groups (15.0 and 17.0 months, log-rank test $p=0.57$ ). In the multivariate Cox's proportional hazard model, the adjusted hazard ratio (HRadj) was statistically significant for male sex (HRadj $=5.382,95 \%$ CI: $1.496-19.359 ; p=0.010)$, pathological diagnosis of adenocarcinoma (HRadj $=0.460,95 \%$ CI: $0.223-0.948 ; p=0.035)$, and epithelial growth factor receptor negative mutation (HRadj $=6.040,95 \%$ CI: $1.158-31.497 ; p=0.033$ ), but not for the presence of COPD (HRadj $=0.661,95 \%$ CI: $0.330-1.325 ; p=0.24$ ). Toxicity profile in COPD group was favorable, as in the non-COPD group.

Conclusion: Mild to moderate COPD did not have a significant deleterious impact on toxicity and prognosis in NSCLC patients.

Keywords: toxicity, survival, prognostic factors

\section{Introduction}

Lung cancer (LC) is currently the most common cancer worldwide. Despite years of clinical research and the development of multiple chemotherapeutic regimens, survival of patients with advanced LC remains dismal. Among LC diagnoses, the majority are of non-small cell LC (NSCLC). Several factors, such as sex, performance status (PS), epithelial growth factor receptor (EGFR) mutation status, and the presence of comorbidities, are reported to be associated with prognosis in advanced NSCLC. ${ }^{1,2}$ The presence of comorbidities influences not only prognosis but also management, because patients with comorbidities are less likely to receive chemotherapy. ${ }^{3}$ 
COPD is regarded as one of the important comorbidities in NSCLC patients, with a prevalence of $50 \%-70 \% .^{4-7}$ On the other hand, patients with COPD also have an increased risk of LC. Previous studies have reported that the main cause of death in patients with severe COPD is respiratory failure, whereas LC and cardiovascular disease are the predominant causes in patients with mild to moderate COPD. ${ }^{8}$ The severity of COPD in patients with newly diagnosed LC is usually classified as mild to moderate. ${ }^{69}$ Most advanced NSCLC patients with mild to moderate COPD are treated with chemotherapy; therefore, addressing the potential impact of COPD on treatment outcomes of NSCLC patients may be crucial in optimizing the management and prognosis of NSCLC patients. However, whether mild to moderate COPD impacts the feasibility for and prognosis after chemotherapy for NSCLC patients has not been well studied because pulmonary function tests are not usually conducted in these patients.

Here, we conducted a pulmonary function test for NSCLC patients before treatment and assessed the presence and severity of COPD. The aim of this study was to elucidate the impact of mild to moderate COPD on the feasibility for and prognosis after chemotherapy in NSCLC patients.

\section{Material and methods Study subjects}

The medical records of 268 consecutive patients with NSCLC who received first-line cytotoxic chemotherapy at Nagoya University Hospital between January 2009 and December 2014 were retrospectively reviewed. Data were collected from our institutional cancer registry database and patient follow-up visits. We excluded 183 patients for the following reasons: 1) treatment with radiochemotherapy or tyrosine kinase inhibitors (TKIs) as first-line chemotherapy, 2) unavailability of pulmonary function test data, and 3) severe COPD. Finally, 85 evaluable patients were included.

Of these 85 patients, 43 patients were diagnosed with COPD, and 42 patients did not have COPD (non-COPD; Figure 1). Twenty-seven patients were classified as having mild COPD and 16 patients as having moderate COPD, according to the spirometric criteria of the Global Initiative for Chronic Obstructive Lung Disease as follows: 1) nonCOPD: forced expiratory volume in $1 \mathrm{~s}\left(\mathrm{FEV}_{1}\right) /$ forced vital capacity (FVC) $\geq 70 \%$, 2) mild COPD: $\mathrm{FEV}_{1} / \mathrm{FVC}<70 \%$ and $\mathrm{FEV}_{1} \geq 80 \%$ predicted, 3) moderate COPD: $\mathrm{FEV}_{1}$ l $\mathrm{FVC}<70 \%$ and $50 \% \leq \mathrm{FEV}_{1}<80 \%$ predicted, and 4) severe COPD: $\mathrm{FEV}_{1} / \mathrm{FVC}<70 \%$ and $30 \% \leq \mathrm{FEV}_{1}<50 \%$ predicted. ${ }^{10}$ Based on clinical data, we excluded patients who

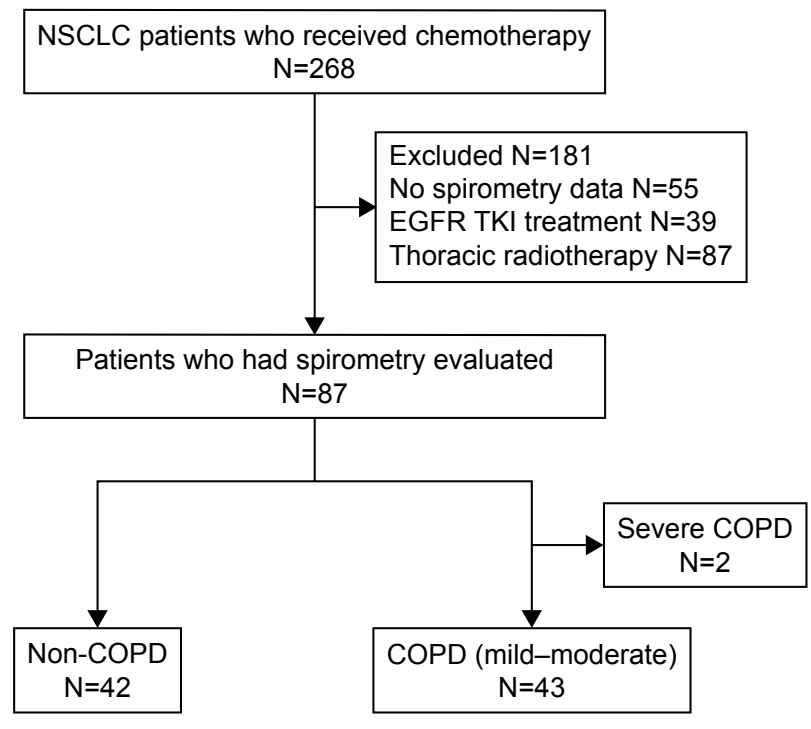

Figure I Screening and inclusion process for patients in the study.

Note: Forty-three patients with COPD and 42 patients without COPD were included in this study.

Abbreviations: EGFR, epidermal growth factor receptor; NSCLC, non-small cell lung cancer; TKI, tyrosine kinase inhibitor.

had history or evidence of other diseases with chronic airflow obstruction such as asthma, bronchiectasis, tuberculosis, and cystic fibrosis from this study.

We evaluated the objective response rates (ORR), disease control rate (DCR), median overall survival (OS), and toxicity profiles and compared these between patients with COPD and non-COPD.

This study was approved by the Nagoya University Hospital Institutional Review Board (IRB, No 2016-0222). The requirement for informed consent from the patients of this study was waived by the IRB due to the retrospective nature, and any personal information from the data was removed beforehand.

\section{Data collection}

The data collected for all patients included age, sex, smoking habit, pack-years index, symptoms, PS on the Eastern Cooperative Oncology Group scale, tumor-node-metastasis staging, histology, laboratory data, spirometric values, treatment, toxicity profiles, and survival.

\section{Outcomes and toxicities}

OS was measured as the period from the diagnosis of LC to death. ORR was assessed using the Response Evaluation Criteria in Solid Tumors. Clinical benefit was defined as complete response (CR), partial response (PR), stable disease, or progressive disease (PD), and from these data, DCR (CR + $\mathrm{PR}+$ stable disease $)$ and $\mathrm{ORR}(\mathrm{CR}+\mathrm{PR})$ were determined. 
All toxicities were graded according to the Common Terminology Criteria for Adverse Events version 4.0.

\section{Statistical analysis}

All values are presented as means \pm standard deviation or median (range). The chi-squared test or Fisher's exact test was used for categorical data, and the Mann-Whitney $U$ test was used for continuous data. Differences in the values for pulmonary function tests were evaluated using the paired Student's $t$-test. Chi-squared statistics or Fisher's exact test was used to compare proportions. Survival curves were compared with the log-rank test, and Kaplan-Meier survival curves were plotted. Cox's proportional hazards models were used to adjust for age, sex, tumor stage, PS, pathological diagnosis, EGFR mutation status, and the presence of COPD. All data were analyzed using a statistical software package (SPSS, version 23.0; SPSS, Inc., Chicago, IL, USA).

\section{Results}

\section{Patient characteristics}

The baseline patient characteristics are shown in Table 1. The mean age of patients with COPD was higher compared to those with non-COPD, and the proportion of never-smoker was lower in patients with COPD than those with non-COPD. There were significant differences in COPD-related symptoms such as dyspnea and sputum between the COPD group and non-COPD group. There were no significant differences in sex, PS, histological subtype, tumor stage, and EGFR mutation status.

As for baseline physiological data, there were no significant differences in baseline laboratory data including total protein, albumin, creatinine, total bilirubin, glutamic oxaloacetic transaminase, and glutamic-pyruvic transaminase.

\section{Treatment and response}

As shown in Table 2, the most frequently administered regimen was carboplatin-based doublet chemotherapy (76.5\%) in both COPD and non-COPD patients, and the treatment cycles did not differ between the groups $(p=0.15)$. Nine patients were positive for EGFR mutation and received EGFR-TKI treatment after the failure of first-line chemotherapy. Six COPD patients and five non-COPD patients received adjuvant chemotherapy.

The ORR and DCR were $38.9 \%$ and $58.3 \%$, respectively, in patients with COPD and $22.9 \%$ and $57.1 \%$, respectively, in patients with non-COPD. There was no significant difference in ORR ( $p=0.14)$ or DCR $(p=0.92)$ between COPD and non-COPD patients.
Table I Patient characteristics and baseline physiological data depending on the presence or absence of COPD

\begin{tabular}{|c|c|c|c|c|c|}
\hline & COPD & $\%$ & Non-COPD & $\%$ & $p$-value \\
\hline $\mathrm{N}$ & 43 & & 42 & & \\
\hline Male sex & 37 & 86 & 32 & 76 & 0.25 \\
\hline Age, years & $67 \pm 8$ & & $63 \pm 8$ & & 0.018 \\
\hline $\begin{array}{l}\text { Smoking history, never } \\
\text { smoker }\end{array}$ & 2 & 5 & 9 & 21 & 0.021 \\
\hline Smoking status, pack-years & $58.5 \pm 37.0$ & & $41.9 \pm 31.8$ & & 0.28 \\
\hline \multicolumn{6}{|c|}{ Symptoms related to COPD } \\
\hline Dyspnea, $\mathrm{n}$ & 14 & 33 & 0 & 0 & $<0.001$ \\
\hline Cough, $\mathrm{n}$ & 23 & 53 & 16 & 38 & 0.15 \\
\hline Sputum, $\mathrm{n}$ & 16 & 37 & 6 & 14 & 0.016 \\
\hline \multicolumn{6}{|l|}{ PS (ECOG) } \\
\hline 0 & 25 & & 19 & & 0.28 \\
\hline I & 18 & & 23 & & \\
\hline \multicolumn{6}{|l|}{ Histology } \\
\hline Adenocarcinoma & 28 & & 27 & & I \\
\hline Squamous cell carcinoma & 7 & & 6 & & \\
\hline Large cell carcinoma & 0 & & I & & \\
\hline Others & 8 & & 8 & & \\
\hline \multicolumn{6}{|l|}{ EGFR mutation status } \\
\hline Mutant & 3 & & 6 & & 0.27 \\
\hline Wild & 31 & & 32 & & \\
\hline Not assessed & 9 & & 4 & & \\
\hline \multicolumn{6}{|l|}{ Stage } \\
\hline IA & I & & 0 & & 0.15 \\
\hline IB & 3 & & I & & \\
\hline $2 A$ & 1 & & 0 & & \\
\hline $2 B$ & 0 & & 2 & & \\
\hline $3 \mathrm{~A}$ & 7 & & 4 & & \\
\hline $3 B$ & 2 & & 4 & & \\
\hline 4 , recurrence & 29 & & 31 & & \\
\hline \multicolumn{6}{|c|}{ Pulmonary function test } \\
\hline FVC, L & $3.37 \pm 0.80$ & & $3.04 \pm 0.81$ & & 0.06 \\
\hline FVC, \% & $106.2 \pm 19.9$ & & $95.0 \pm 19.6$ & & 0.01 \\
\hline $\mathrm{FEV}_{1}, \mathrm{~L}$ & $2.15 \pm 0.55$ & & $2.34 \pm 0.60$ & & 0.14 \\
\hline $\mathrm{FEV}_{1}, \%$ & $91.2 \pm 21.0$ & & $95.0 \pm 18.8$ & & 0.39 \\
\hline$\% \mathrm{FEV}_{1}$ & $64.1 \pm 5.5$ & & $77.7 \pm 6.1$ & & $<0.001$ \\
\hline \multicolumn{6}{|l|}{ GOLD stage } \\
\hline Mild, n & 27 & & - & & \\
\hline Moderate, $\mathrm{n}$ & 16 & & - & & \\
\hline \multicolumn{6}{|l|}{ Treatment } \\
\hline LAMA, $\mathrm{n}$ & 5 & 12 & 0 & 0 & \\
\hline LABA, $n$ & 6 & 14 & I & 2 & \\
\hline ICS, n & 5 & 12 & 0 & 0 & \\
\hline SABA, $n$ & I & 2 & 0 & 0 & \\
\hline \multicolumn{6}{|l|}{ Laboratory data } \\
\hline $\mathrm{TP}$ & $7.0 \pm 0.6$ & & $6.9 \pm 0.6$ & & 0.69 \\
\hline Albumin & $3.6 \pm 0.5$ & & $3.6 \pm 0.6$ & & 0.75 \\
\hline Creatinine & $0.76 \pm 0.21$ & & $0.70 \pm 0.19$ & & 0.18 \\
\hline T-bil & $0.5 I \pm 0.23$ & & $0.61 \pm 0.26$ & & 0.28 \\
\hline GOT & $22.7 \pm 10.4$ & & $21.1 \pm 9.9$ & & 0.47 \\
\hline GPT & $19.6 \pm 13.5$ & & $21.7 \pm 17.6$ & & 0.53 \\
\hline
\end{tabular}

Notes: Data are presented as number, or mean \pm standard deviation. '-' indicates no data.

Abbreviations: ECOG, Eastern Cooperative Oncology Group; EGFR, epithelial growth factor receptor; $\mathrm{FEV}_{1}$, forced expiratory volume in I s; FVC, forced vital capacity; GOLD, Global Initiative for Chronic Obstructive Lung Disease; GOT, glutamic oxaloacetic transaminase; GPT, glutamic-pyruvic transaminase; ICS, inhaled corticosteroids; LABA, long-acting beta-adrenoceptor agonist; LAMA, long-acting muscarinic antagonist; PS, performance status; SABA, short-acting beta-adrenoceptor agonist; T-bil, total bilirubin; TP, total protein. 
Table 2 Treatment and outcome

\begin{tabular}{llll}
\hline & COPD & Non-COPD & p-value \\
\hline $\mathrm{N}$ & 43 & 42 & \\
First-line chemotherapy & & & \\
Platinum-based doublet & & & \\
CBDCA base & 35 & 30 & \\
CDDP base & 5 & 8 & \\
Single agent & 3 & 4 & 0.15 \\
Cycles & & & \\
I-2 & 11 & 8 & \\
$3-4$ & 27 & 22 & \\
$5-6$ & 5 & 12 & \\
Treatment outcome & & & \\
$\mathrm{N}$ & 37 & 37 & \\
CR, n & 0 & 0 & \\
PR, $\mathrm{n}$ & 14 & 8 & \\
SD, $\mathrm{n}$ & 7 & 12 & \\
PD, $\mathrm{n}$ & 15 & 15 & 0.14 \\
NE, $\mathrm{n}$ & $\mathrm{I}$ & 2 & 0.92 \\
Response & & & \\
$\mathrm{N}$ & 36 & 35 & \\
ORR, \% & 38.9 & 22.9 & \\
DCR, \% & 58.3 & 57.1 & \\
\hline Note Dat & & & \\
\hline
\end{tabular}

Note: Data are presented as number or percent.

Abbreviations: CBDCA, carboplatin; CDDP, cisplatin; CR, complete response; $\mathrm{DCR}$, disease control rate; NE, not evaluated; ORR, overall response rate; PD, progressive disease; PR, partial response; SD, stable disease.

\section{Prognosis}

The Kaplan-Meier curves for COPD and non-COPD patients are shown in Figure 2A. The median OS in COPD and nonCOPD patients was 15.0 and 17.0 months, respectively, and the difference did not reach significance (log-rank test, $p=0.57)$. This result was unchanged even when we

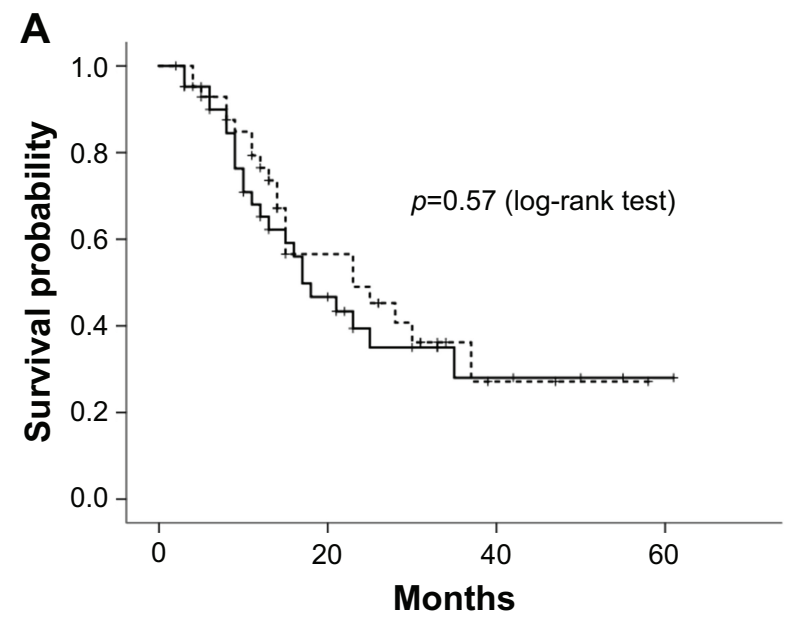

excluded patients who received adjuvant chemotherapy $(p=0.88$; Figure 2B).

In the univariate Cox's proportional hazard analyses for factors affecting OS, male sex (hazard ratio [HR] $=3.536$, 95\% CI: 1.092-11.450; $p=0.035)$, pathological diagnosis of adenocarcinoma (HR $=0.486,95 \%$ CI: 0.259-0.911; $p=0.024)$, and EGFR negative mutation $(\mathrm{HR}=5.655,95 \% \mathrm{CI}$ : $1.304-24.519 ; p=0.021)$ were significantly associated with survival. In the multivariate Cox's proportional hazard model adjusting for the most relevant variables, the adjusted hazard ratio (HRadj) was statistically significant for male sex $($ HRadj $=5.382$, 95\% CI: 1.496-19.359; $p=0.010$ ), pathological diagnosis of adenocarcinoma $($ HRadj $=0.460$, 95\% CI: $0.223-0.948 ; p=0.035)$, and EGFR negative mutation $($ HRadj $=6.040,95 \%$ CI: 1.158-31.4971; $p=0.033$ ), but not for the presence of COPD (HRadj $=0.661,95 \% \mathrm{CI}$ : $0.330-1.325 ; p=0.24$; Table 3 ).

\section{Toxicity}

The most frequently recorded toxicities are shown in Table 4. In general, treatment was well tolerated, and there were no significant differences in toxicity between COPD and non-COPD patients. Furthermore, there were no significant differences in grades 3-4 severe toxicity between the patient groups. Neutropenia was the most frequent grades 3-4 toxicity in each group. There were no treatment-related deaths.

\section{Discussion}

In the present study, mild to moderate COPD did not have a significant impact on feasibility and tumor response for

B

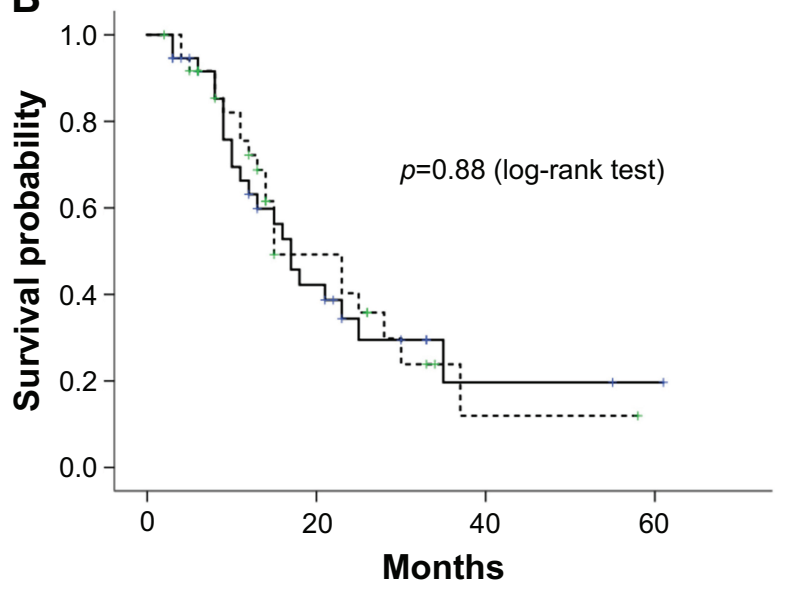

Figure 2 Kaplan-Meier survival curves for overall survival.

Notes: (A) All patients: COPD patients ( $n=43$; dashed line) and non-COPD patients ( $n=42$; solid line). (B) Excluding patients who received adjuvant chemotherapy: COPD patients ( $n=37$; dashed line) and non-COPD patients ( $n=37$; solid line). 
Table 3 Cox's proportional hazards analyses for factors affecting OS

\begin{tabular}{|c|c|c|c|c|c|c|}
\hline & \multicolumn{3}{|c|}{ Univariate } & \multicolumn{3}{|c|}{ Multivariate } \\
\hline & HR & $95 \% \mathrm{Cl}$ & $p$-value & HR & $95 \% \mathrm{Cl}$ & p-value \\
\hline Age & 0.938 & $0.964-1.034$ & 1.0 & 0.998 & $0.962-1.036$ & 0.938 \\
\hline Male sex & 3.536 & $1.092-11.450$ & 0.035 & 5.382 & $1.496-19.359$ & 0.010 \\
\hline PS & 1.513 & $0.822-2.785$ & 0.18 & 1.714 & $0.872-3.370$ & 0.12 \\
\hline Clinical stage* & 1.114 & $0.38 I-3.258$ & 0.84 & - & - & - \\
\hline Adenocarcinoma & 0.486 & $0.259-0.911$ & 0.024 & 0.460 & $0.259-0.911$ & 0.035 \\
\hline EGFR mutation negative & 5.655 & $1.304-24.519$ & 0.021 & 6.040 & I.I58-31.497 & 0.033 \\
\hline Presence of COPD & 0.956 & $0.525-1.742$ & 0.88 & 0.661 & $0.330-1.325$ & 0.24 \\
\hline
\end{tabular}

Notes: *Stage $3 \mathrm{~A}+3 \mathrm{~B}$ vs 4 + recurrence. "-" indicates no data.

Abbreviations: EGFR, epithelial growth factor receptor; HR, hazard ratio; PS, performance status; OS, overall survival.

NSCLC patients who received first-line cytotoxic chemotherapy. In addition, mild to moderate COPD was not significantly associated with survival of these patients. The presence of mild to moderate COPD might not be a concern for withholding chemotherapy in NSCLC patients.

Regarding prognosis, mild to moderate COPD was not significantly associated with survival of NSCLC patients in our study. Several prognostic factors such as age, tumor stage, pathology, and EGFR mutation status have been reported in NSCLC patients. ${ }^{211}$ In our study, there were no significant differences in these factors between COPD and non-COPD groups. Moreover, we excluded NSCLC patients treated with radiochemotherapy or EGFR-TKI therapy to minimize the impact of treatment intensity on prognosis in comparison of COPD and non-COPD patients, because there are substantial differences in the effectiveness and toxicity profiles of cytotoxic chemotherapy and radiochemotherapy or EGFRTKI therapy. ${ }^{11-13}$ Consistent with our results, a previous study showed that the presence of COPD was not associated with poor prognosis of NSCLC patients who received chemotherapy or EGFR-TKI therapy. ${ }^{11}$ Moreover, it remains controversial whether the presence of mild to moderate COPD is associated with prognosis of NSCLC patients who undergo lung resection. ${ }^{6,14,15}$ These data suggested that mild to moderate COPD did not have a significant impact on prognosis in NSCLC patients. Another explanation for our results is that there were no significant differences in ORR and toxicity profile of chemotherapy between patients with COPD and non-COPD. Severe toxicity during chemotherapy for NSCLC patients tends to result in early treatment termination, which decreases the efficacy of chemotherapy. ${ }^{16}$ In our study, there were no significant differences in chemotherapy cycles between COPD and non-COPD patients.

In our study, there was no significant difference in ORR between COPD and non-COPD patients. Previous studies reported that patients with smoking-related LC showed higher prevalence of squamous cell carcinoma, which has been reported to be more resistant to chemotherapy than adenocarcinoma. ${ }^{17}$ The majority of patients in our study with mild to moderate COPD were pathologically diagnosed with adenocarcinoma, which might therefore have affected the effectiveness of chemotherapy. Our previous study showed that the severity of COPD in Japanese patients with newly diagnosed LC was classified mainly as mild to moderate. ${ }^{6,18}$ In addition, previous studies reported that adenocarcinoma was the major pathological type in NSCLC patients with

Table 4 Adverse events

\begin{tabular}{|c|c|c|c|c|c|c|}
\hline & \multicolumn{3}{|l|}{ All } & \multicolumn{3}{|c|}{ Grade 3 or 4} \\
\hline & COPD & Non-COPD & p-value & COPD & Non-COPD & $p$-value \\
\hline Leukocytopenia & 23 & 19 & 0.45 & 3 & 2 & 0.70 \\
\hline Neutropenia & 32 & 26 & 0.22 & 13 & 12 & 0.87 \\
\hline Febrile neutropenia & - & - & - & 2 & 0 & 0.49 \\
\hline Anemia & 35 & 34 & 0.96 & 5 & 3 & 0.48 \\
\hline Thrombocytopenia & 24 & 28 & 0.31 & 5 & 4 & 0.58 \\
\hline Nausea & 15 & 17 & 0.6 & 4 & 4 & 0.19 \\
\hline Vomiting & 2 & 3 & 0.63 & 0 & 0 & - \\
\hline Fatigue & 11 & 9 & 0.65 & I & 0 & 0.32 \\
\hline Neuropathy & 9 & 9 & 0.96 & 4 & I & 0.18 \\
\hline Severe adverse event & - & - & - & 23 & 18 & 0.33 \\
\hline
\end{tabular}

Note: “-” indicates no data. 
mild to moderate COPD. ${ }^{5,6,11}$ These studies support our result showing a high prevalence of adenocarcinoma in patients with mild to moderate COPD.

There are limited data concerning the impact of mild to moderate COPD on the toxicity profiles of cytotoxic chemotherapy. NSCLC patients who receive chemotherapy frequently experience adverse events such as hematological, gastrointestinal, or neurological toxicity. ${ }^{12,16}$ In our study, there were no significant differences in toxicity profile of chemotherapy between patients with mild to moderate COPD and non-COPD. This result may be explained by the exclusion of patients with severe COPD in this study. Compared with patients with mild to moderate COPD, these patients have a higher risk of respiratory symptoms and functional impairment, which is associated with excess toxicity during cytotoxic chemotherapy. ${ }^{19-22}$ Most COPD patients in our study had good PS, and, therefore, the toxicity profile of patients with COPD was as favorable as that of patients with non-COPD.

On the other hand, previous studies reported that after lung resection, NSCLC patients with mild to moderate COPD had greater risk of postoperative complications, such as respiratory complications and cardiac arrhythmias, compared with those without COPD. ${ }^{7,23}$ NSCLC patients who undergo lung resection are subjected to general anesthesia, reduction of lung volume, and loss of inspiratory and expiratory tones. ${ }^{24,25}$ There are considerable differences in the impact of these interventions on respiratory systems between patients treated with lung resection and those who receive chemotherapy, and these differences may account for the distinct feasibility of these interventions for NSCLC patients with mild to moderate COPD.

The limitations of this study are as follows. First, the study was retrospective, and patients (20.5\%) on whom spirometry was not conducted were excluded. Second, we used the COPD definition $\left(\mathrm{FEV}_{1} / \mathrm{FVC}<0.7\right)$ for diagnosing COPD, which might tend to overdiagnose COPD especially in the elderly because the $\mathrm{FEV}_{1}$ value decreases more quickly with age than the FVC. ${ }^{26}$ In this study, 44\% (19/43) of patients were elderly (age $\geq 70$ ), and the COPD group was significantly older than the non-COPD group. Therefore, there might be a possibility that some patients were overdiagnosed as COPD. However, the data that the COPD-related symptoms such as dyspnea and sputum were more frequently seen in the COPD group than in the nonCOPD group supported the diagnostic accuracy for COPD in our cohort. Third, we excluded NSCLC patients who had received EGFR-TKI therapy as first-line chemotherapy because we aimed to investigate the impact of COPD on the effectiveness and toxicity of cytotoxic chemotherapy in this study. Compared with patients with COPD, those without COPD were reported to show a higher likelihood of EGFR mutation positivity and consequently tend to receive EGFRTKI therapy. ${ }^{6,27}$ Therefore, we might have recruited more patients with COPD than without COPD, thereby leading to selection bias. Fourth, the severity of air flow limitation in our cohort was restricted to mild to moderate. Severe COPD patients tend to suffer from malnutrition and functional impairment, and therefore, they are likely to have more toxicity or less effective therapy. ${ }^{8,19,20,28}$ In this study, we could not assess the impact of severe COPD on prognosis and toxicity of chemotherapy. Further investigation is needed to clarify whether severe COPD has an impact on toxicity and prognosis of NSCLC patients.

\section{Conclusion}

In summary, mild to moderate COPD did not have a significant deleterious impact on toxicity and prognosis in patients with NSCLC. The presence of mild to moderate COPD might not be a concern for withholding cytotoxic chemotherapy as first-line therapy in NSCLC patients.

\section{Acknowledgments}

The abstract of this manuscript was presented as a poster presentation during the American Thoracic Society International Conference in May 2017 in San Francisco. The abstract was published in the ATS International Congress 2017 Abstracts (http://www.atsjournals.org/doi/ pdf/10.1164/ajrccm-conference.2017.195.1 MeetingAbstracts.A4581).

\section{Author contributions}

$\mathrm{NO}$ and $\mathrm{NH}$ contributed to study design, data collection, data analysis, review, writing, and submission of this manuscript. MM contributed to study design, review, writing, and submission of this manuscript. KS contributed to review, writing, and submission of this manuscript. SM, AA, and YN contributed to review of this manuscript. YH contributed to study design and review of this manuscript. All authors contributed toward data analysis, drafting and revising the paper and agree to be accountable for all aspects of the work.

\section{Disclosure}

The authors report no conflicts of interest in this work. 


\section{References}

1. Asmis TR, Ding K, Seymour L, et al. Age and comorbidity as independent prognostic factors in the treatment of non small-cell lung cancer: a review of National Cancer Institute of Canada Clinical Trials Group trials. J Clin Oncol. 2008;26(1):54-59.

2. Rosell R, Moran T, Queralt C, et al; Spanish Lung Cancer Group. Screening for epidermal growth factor receptor mutations in lung cancer. N Engl J Med. 2009;361(10):958-967.

3. Ramsey SD, Howlader N, Etzioni RD, Donato B. Chemotherapy use, outcomes, and costs for older persons with advanced non-small-cell lung cancer: evidence from surveillance, epidemiology and end resultsMedicare. J Clin Oncol. 2004;22(24):4971-4978.

4. Loganathan RS, Stover DE, Shi W, Venkatraman E. Prevalence of COPD in women compared to men around the time of diagnosis of primary lung cancer. Chest. 2006;129(5):1305-1312.

5. Young RP, Hopkins RJ, Christmas T, Black PN, Metcalf P, Gamble GD. COPD prevalence is increased in lung cancer, independent of age, sex and smoking history. Eur Respir J. 2009;34(2):380-386.

6. Hashimoto N, Matsuzaki A, Okada Y, et al. Clinical impact of prevalence and severity of COPD on the decision-making process for therapeutic management of lung cancer patients. BMC Pulm Med. 2014;14:14.

7. Osuka S, Hashimoto N, Sakamoto K, Wakai K, Yokoi K, Hasegawa Y. Risk stratification by the lower limit of normal of FEV1/FVC for postoperative outcomes in patients with COPD undergoing thoracic surgery. Respir Investig. 2015;53(3):117-123.

8. Sin DD, Anthonisen NR, Soriano JB, Agusti AG. Mortality in COPD: role of comorbidities. Eur Respir J. 2006;28(6):1245-1257.

9. Matsuo M, Hashimoto N, Usami N, et al. Inspiratory capacity as a preoperative assessment of patients undergoing thoracic surgery. Interact Cardiovasc Thorac Surg. 2012;14(5):560-564.

10. Global Initiative for Chronic Obstructive Lung Disease. Global strategy for the diagnosis, management, and prevention of chronic obstructive pulmonary disease-2016: Available from: http:/goldcopd.org/globalstrategy-diagnosis-management-prevention-copd-2016/. Accessed April 17, 2017

11. Izquierdo JL, Resano P, El Hachem A, Graziani D, Almonacid C, Sanchez IM. Impact of COPD in patients with lung cancer and advanced disease treated with chemotherapy and/or tyrosine kinase inhibitors. Int J Chron Obstruct Pulmon Dis. 2014;9:1053-1058.

12. Maemondo M, Inoue A, Kobayashi K, et al; North-East Japan Study Group. Gefitinib or chemotherapy for non-small-cell lung cancer with mutated EGFR. N Engl J Med. 2010;362(25):2380-2388.

13. Mok TS, Wu YL, Thongprasert S, et al. Gefitinib or carboplatinpaclitaxel in pulmonary adenocarcinoma. N Engl J Med. 2009;361(10): 947-957.

14. Lee SJ, Lee J, Park YS, et al. Impact of chronic obstructive pulmonary disease on the mortality of patients with non-small-cell lung cancer. J Thorac Oncol. 2014;9(6):812-817.
15. Gao YH, Guan WJ, Liu Q, et al. Impact of COPD and emphysema on survival of patients with lung cancer: a meta-analysis of observational studies. Respirology. 2016;21(2):269-279.

16. Kato T, Morise M, Ando M, et al. Can we predict the development of serious adverse events (SAEs) and early treatment termination in elderly non-small cell lung cancer (NSCLC) patients receiving platinum-based chemotherapy? J Cancer Res Clin Oncol. 2016;142(7):1629-1640.

17. Hirsch FR, Spreafico A, Novello S, Wood MD, Simms L, Papotti M. The prognostic and predictive role of histology in advanced non-small cell lung cancer: a literature review. J Thorac Oncol. 2008;3(12): 1468-1481.

18. Matsuzaki A, Hashimoto N, Okachi S, et al. Clinical impact of the lower limit of normal of FEV1/FVC on survival in lung cancer patients undergoing thoracic surgery. Respir Investig. 2016;54(3):184-192.

19. Jones PW, Adamek L, Nadeau G, Banik N. Comparisons of health status scores with MRC grades in COPD: implications for the GOLD 2011 classification. Eur Respir J. 2013;42(3):647-654.

20. Cruz J, Marques A, Jácome C, Gabriel R, Figueiredo D. Global functioning of COPD patients with and without functional balance impairment: an exploratory analysis based on the ICF framework. COPD. 2015; 12(2):207-216.

21. Neder JA, O’Donnell CD, Cory J, et al. Ventilation distribution heterogeneity at rest as a marker of exercise impairment in mild-to-advanced COPD. COPD. 2015;12(3):249-256.

22. Mörth C, Valachis A. Single-agent versus combination chemotherapy as first-line treatment for patients with advanced non-small cell lung cancer and performance status 2: a literature-based meta-analysis of randomized studies. Lung Cancer. 2014;84(3):209-214.

23. Sekine Y, Behnia M, Fujisawa T. Impact of COPD on pulmonary complications and on long-term survival of patients undergoing surgery for NSCLC. Lung Cancer. 2002;37(1):95-101.

24. Yabuuchi H, Kawanami S, Kamitani T, et al. Prediction of post-operative pulmonary function after lobectomy for primary lung cancer: a comparison among counting method, effective lobar volume, and lobar collapsibility using inspiratory/expiratory CT. Eur J Radiol. 2016;85(11): 1956-1962.

25. Pelletier C, Lapointe L, LeBlanc P. Effects of lung resection on pulmonary function and exercise capacity. Thorax. 1990;45(7):497-502.

26. Hardie JA, Buist AS, Vollmer WM, Ellingsen I, Bakke PS, Morkve O. Risk of over-diagnosis of COPD in asymptomatic elderly never-smokers. Eur Respir J. 2002;20(5):1117-1122.

27. Lim JU, Yeo CD, Rhee CK, et al. Chronic obstructive pulmonary diseaserelated non-small-cell lung cancer exhibits a low prevalence of EGFR and ALK driver mutations. PLoS One. 2015;10(11):e0142306.

28. Chatila WM, Thomashow BM, Minai OA, Criner GJ, Make BJ. Comorbidities in chronic obstructive pulmonary disease. Proc Am Thorac Soc. 2008;5(4):549-555.
International Journal of COPD

\section{Publish your work in this journal}

The International Journal of COPD is an international, peer-reviewed journal of therapeutics and pharmacology focusing on concise rapid reporting of clinical studies and reviews in COPD. Special focus is given to the pathophysiological processes underlying the disease, intervention programs, patient focused education, and self management protocols.

\section{Dovepress}

This journal is indexed on PubMed Central, MedLine and CAS. The manuscript management system is completely online and includes a very quick and fair peer-review system, which is all easy to use. Visit http://www.dovepress.com/testimonials.php to read real quotes from published authors. 